\title{
Effect on Human Health by Residues of Commonly Used Pesticides in Vegetables Cultivation
}

\author{
Farzana Khalil, Maliyat Tarannum Maruf, Mohammad Tariqul Islam, Mohammad Mahbub Rabbani, \\ S. Mosaddeq Ahmed
}

\begin{abstract}
People in Bangladesh are over scared for toxicity of vegetables \& fruits, because the educational level of the farmers is not up to the mark. Farmers apply pesticides randomly on agricultural fields without maintaining pre-harvest intervals and dose. The aim of this work was to study dissipation pattern of some pesticides in some vegetables kept at room temperature which represent market condition and to identify and quantify pesticides applied on some vegetables. By interviewing the farmers, three commonly used pesticides; cypermethrin, chlorpyrifos and fenvalerate were sprayed in the farmer's fields of the western part of Bangladesh. Samples were extracted by QuEChERS method, cleaned-up by adsorption chromatography technique, and analyzed by GC-ECD technique. Recoveries were found to be between $87-107 \%$ with RSD lower than $10 \%$ at three spiking levels. Matrix matched calibration curves were linear for all the analytes with $r^{2} \geq 0.99$. LODs were found to be $0.01 \mathrm{mg} / \mathrm{kg}$ for cypermethrin and $0.002 \mathrm{mg} / \mathrm{kg}$ for both of fenvalerate and chlorpyrifos. The samples of the same cultivar's variety were purchased from the markets of Savar, Mymensingh and Cumilla. Our finding showed only the presence of cypermethrin in tomato but the values were below MRL and no pesticide residue was found in eggplant.
\end{abstract}

Index Terms-Pesticide residues, health hazard, tomato, eggplant, pre-harvest intervals.

Farzana Khalil

American International University-Bangladesh

Dhaka, Bangladesh

farzana.khalil@aiub.edu

Maliyat Tarannum Maruf

Monash University, Melbourne, Australia

maliyatlamisa1023@gmail.com

Mohammad Tariqul Islam

American International University-Bangladesh

Dhaka, Bangladesh

tariquldu@aiub.edu

Mohammad Mahbub Rabbani

American International University-Bangladesh

Dhaka, Bangladesh

mmrabbani@aiub.edu

S. Mosaddeq Ahmed

American International University-Bangladesh

Dhaka, Bangladesh

smahmed@aiub.edu

\section{INTRODUCTION}

$F_{p}$ ood products can be contaminated by several sources and processes through the food chain from production to consumption. This contamination has a harmful effect on the quality of the foodstuff and may posture a health risk. It is essential to ensure contaminant levels not to exceed Maximum Limits (MLs) for the protection of public health. Nowadays concerns regarding contamination in foodstuffs are a major issue in all countries especially in Bangladesh.

Organophosphate insecticides break down very rapidly and hence have very low persistence in the environment. Therefore, they do not cause any long-term hazards. However, these compounds are extensively toxic in nature. Further, due to their instability they must be applied at frequent intervals. Therefore, they are not always economically viable [1].

The most recent group of insecticides is the pyrethroids which have two important advantages, neither persistent nor toxic. It has been observed that metabolites of pyrethroid pesticides are relatively low toxic or non-toxic compared with parent pyrethroid compounds [2]. They were reported to have relatively low toxicity as compared to organophosphorus, organochlorine or carbamate pesticides [3]. Therefore, despite their high cost, they account for about one-third of world insecticides use [4].

Chlorpyrifos (0,0-diethyl 0-3,5,6-trichloro-2-pyridinylphosphorothioate) is a broad-spectrum, chlorinated organophosphate (OP) insecticide, acaricide and nematicide [5]. Cypermethrin [(RS)- $\alpha$-cyano-3-phenoxybenzyl(1RS, 3RS; 1RS, 3RS)-3-(2,2-dichlorovinyl)-2,2-dimethylcyclopropane carboxylate] and fenvalerarte [(RS) - $\alpha$ - cyano -3- phenoxy benzyl (RS) -2- (4-chlorophenyl) -3- methyl butyrate] are the synthetic pyrethroids which have become most important insecticides in wide-scale use. These are effective against the pests which are resistant to organochlorine, organophosphorous, and carbamate insecticides [6]. It has been said that "no pesticide is perfect, but the pyrethroids come close" [7].

Chlorpyrifos may decomposes in plants and produce chlorpyrifos oxon and 3, 5, 6-trichloro-2-pyridinol, which is further degraded to 3, 5, 6-trichloro-methoxypyridine and carbon dioxide [8]. Cypermethrin may photo degrades rapidly and subject to microbial degradation. After photo degradation 
it may produce DCVA, 3- phenoxybenzaldehyde and 3phenoxybenzoic acids [9]. Fenvalerate and its active isomer, esfenvalerate, predominantly undergo ester cleavage through oxidation at the acid and alcohol moieties and conjugation reactions. At $\mathrm{pH} 9.0$ it undergoes ester hydrolysis, resulting in the formation of 2-(4-chlorophenyl)-3-methylbutyric acid (CPIA) as a major degradation product. It is rapidly photodegraded with the action of UV light to the major product, 2(3-phenoxyphenyl)-3-(4-chlorophenyl) methylpentanenitrile (decarboxy-fenvalerate) [10].

The vegetables are low in fat, high in dietary fibers; contain water, minerals and vitamins, possessing a very high nutritional density. So, it is advised peoples to consume more vegetables in meals. But in our country farmers have been using pesticides frequently in vegetables especially on bean, eggplant, cauliflower and tomato to get higher yields. The overdose, frequent uses of pesticides and not following the pre-harvest time frame left residues in food which pollute our food and be harmful for our health. Since it is very difficult to monitor and assess the pesticide contamination, pesticides residue is becoming a foremost food safety concern of consumers and government.

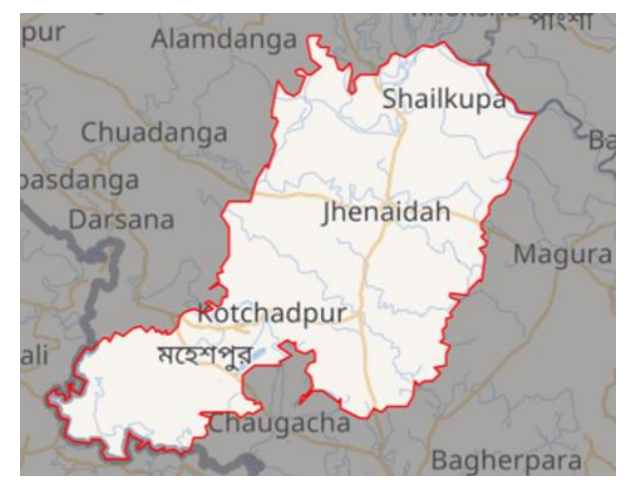

Fig. 1: Jhenaidaha distric of Bangladesh (Coordinates: $\left.23.54^{\circ} \mathrm{N} 89.00^{\circ} \mathrm{E}\right)$

Pesticide usage cannot be properly regulated due to ineffective legislation, lack of awareness and technical knowhow among the farming society in Bangladesh. Bangladesh is an agricultural country. In winter season many vegetables are being cultivated every year more or less in all area of the country. In west and north part of this country vegetables are grown extensively. It has been reported that farmers use pesticides randomly without following the label directions and collect vegetables and sell in market not following the pre-harvest interval. Sometimes they harvest vegetables at the same day or next day after pesticides spraying and these vegetables go to consumers within 2-4 days from pesticides application time. For this reason, vegetables were collected from Jhenidah district (Fig. 1), a western district of Bangladesh after spraying pesticides on vegetables by farmers to see the dissipation pattern of the pesticides kept at room temperature which represent market conditions. The samples of same cultivar's variety were also purchased from the wholesale \& city markets of Savar, Mymensingh and Cumilla district in two different days for each vegetable.
Staff and other facilities of government to perform the necessary monitoring programs are not available. Besides the country is not yet established its own authorized limits for residues and depends upon Codex acceptable limit. So, farmers should be recommended the exact dose to eliminate residual effect of pesticides on consumers. In addition, the preharvest interval of each pesticide should be known so that the amount of residual pesticides in vegetables might be lower than the tolerable range. The present study intended to investigate and quantify the residues of some commonly used pesticides on selected vegetables grown under local agroclimatic conditions of Bangladesh.

In 2003, Anastassiades et al. introduced a new method of analysis, namely QuEChERS, an acronym for quick, easy, cheap, effective, rugged and safe, covers a variety of sample preparation and clean-up techniques for the analysis of multiple pesticide residues in agricultural matrices. The method uses acetonitrile $(\mathrm{MeCN})$ for extraction $(1 \mathrm{~mL}$ MeCN/1 g sample) by twister mixing followed by an addition of 4:1 (w/w) anhydrous $\mathrm{MgSO}_{4}: \mathrm{NaCl}(0.5 \mathrm{~g}$ salts per $\mathrm{g}$ sample) to separate $\mathrm{MeCN}$ extract from the water in the sample. After centrifugation, dispersive solid-phase extraction (dispersive SPE) approach was applied to mix-up $1 \mathrm{~mL}$ of the extract with $25 \mathrm{mg}$ primary secondary amine (PSA) sorbent and $150 \mathrm{mg}$ anhydrous $\mathrm{MgSO}_{4}$. The extract is centrifuged again and transferred to an auto-sampler vial for analysis by gas chromatography/mass spectrometry (GC/MS) and/or other technique. This method is popular due to its simplicity, low cost, less time consuming, reducing glassware and solvent requirement, producing relatively high efficiency results and minimal number of steps it involves [11]. In this study, QuEChERS method of extraction and cleanup was carried out by adsorption column using mixture of florisil, alumina and charcoal. Here GC-ECD was used for analysis of pesticide residues.

\section{EXPERIMENTAL METHODS}

\section{A. Chemicals and Reagents:}

Cypermethrin (91\% purity), chlorpyrifos (99.5\% purity), and fenvalerate (98.5\% purity) purchased from Dr. Ehrenstorfer, Germany were used for analysis and related information of these three pesticides are presented in Table 1. Ethyl acetate, acetone, n-hexane, dichloromethane, methanol (pesticide residue grade), anhydrous magnesium sulphate, sodium chloride (analytical grade), and aluminium oxide (alumina) from Merck, Germany, florisil from ACROS organics, USA, charcoal from Uni-Chem, China were used for this analysis. Florisil and alumina were activated by heating at $105{ }^{\circ} \mathrm{C}$ for 3 $\mathrm{h}$, charcoal was activated by washing with distilled water, nhexane, methanol, acetone in Buchner funnel $\&$ then dried at $105^{\circ} \mathrm{C}$ and all kept in desiccators.

\section{B. Standard Solution Preparation:}

100 ppm primary stock solutions of cypermethrin, chlorpyrifos and fenvalerate were prepared by dissolving an appropriate amount in n-hexane. These primary standard solutions were diluted to $20 \mathrm{ppm}$ and $5 \mathrm{ppm}$ middle and 
working standard solutions respectively. These solutions were labeled indicating name of the standard, concentration and date of preparation. These solutions were stored in amber bottles $(100 \mathrm{~mL})$ in the freezer $\left(-24^{\circ} \mathrm{C}\right)$ away from the pesticide residue laboratory.

\section{Field Experiment and Sampling:}

Eggplant (Solanum melongena var. esculentum) and tomato (Lycopersicon lycopersicum) were collected from the farmer's fields of Jhenidah district (Figure 1). Cypermethrin \& fenvalerate were sprayed by farmers at recommended dose on eggplant in two different fields whereas chlorpyrifos together with cypermethrin were applied on tomato in another field. Before pesticide spraying samples were collected from the respective fields. After two hours samples (nearly $5 \mathrm{~kg}$ ) were collected and one subsample (1 kg) kept in chill-box (0 day sample) and then all the samples were transferred to the laboratory. Control and 0 day samples were kept in freezer and rest of the samples were kept in normal temperature. These normal temperature subsamples were kept in freezer after 1, 3, $5,7 \& 10$ days. Before store in freezer the samples were chopped and homogenized in kitchen blender. and charcoal (10:10:1) in n-hexane. The column was equilibrated with $50 \mathrm{~mL}$-hexane and then the sample extract in n-hexane $(2 \mathrm{~mL})$ was transferred to the column. The column was washed with $20 \mathrm{~mL}$ of $\mathrm{n}$-hexane and eluted with $100 \mathrm{~mL}$

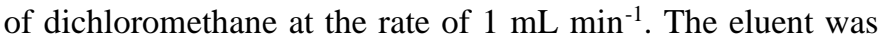
concentrated to dryness on a rotary vacuum evaporator and dissolved the residue in $2 \mathrm{~mL}$ of $\mathrm{n}$-hexane and injected to GCECD. Extraction and purification methods used in this experiment are depicted in Figure 2 using a flow chart.

\section{F. GC-ECD Analysis:}

A gas chromatograph (GC-2010 Shimadzu) equipped with ${ }^{63} \mathrm{Ni}$ Electron Capture, (EC) detector was used in this experiment. A non-polar (Rtx-5 MS) or (HP-5 MS) Quartz capillary column $(30 \mathrm{~m}$ long $\times 250 \mu \mathrm{m}$ i.d. $\times 0.25 \mu \mathrm{m}$ film thicknesses) from Agilent, USA was used to carry out the separation. Nitrogen was used as both carrier (column flow $1.92 \mathrm{~mL} / \mathrm{min}$.) and make up gas. The injector temperature was $220{ }^{\circ} \mathrm{C} \&$ the detector temperature was $290{ }^{\circ} \mathrm{C}$. The injection volume was $1 \mu \mathrm{L}$ and it was carried out in a split-less mode. The oven temperature was set as - initial temperature of 120 ${ }^{\circ} \mathrm{C}$ held for 2 minutes; increased at $10{ }^{\circ} \mathrm{C} \min ^{-1}$ to $270{ }^{\circ} \mathrm{C}$;

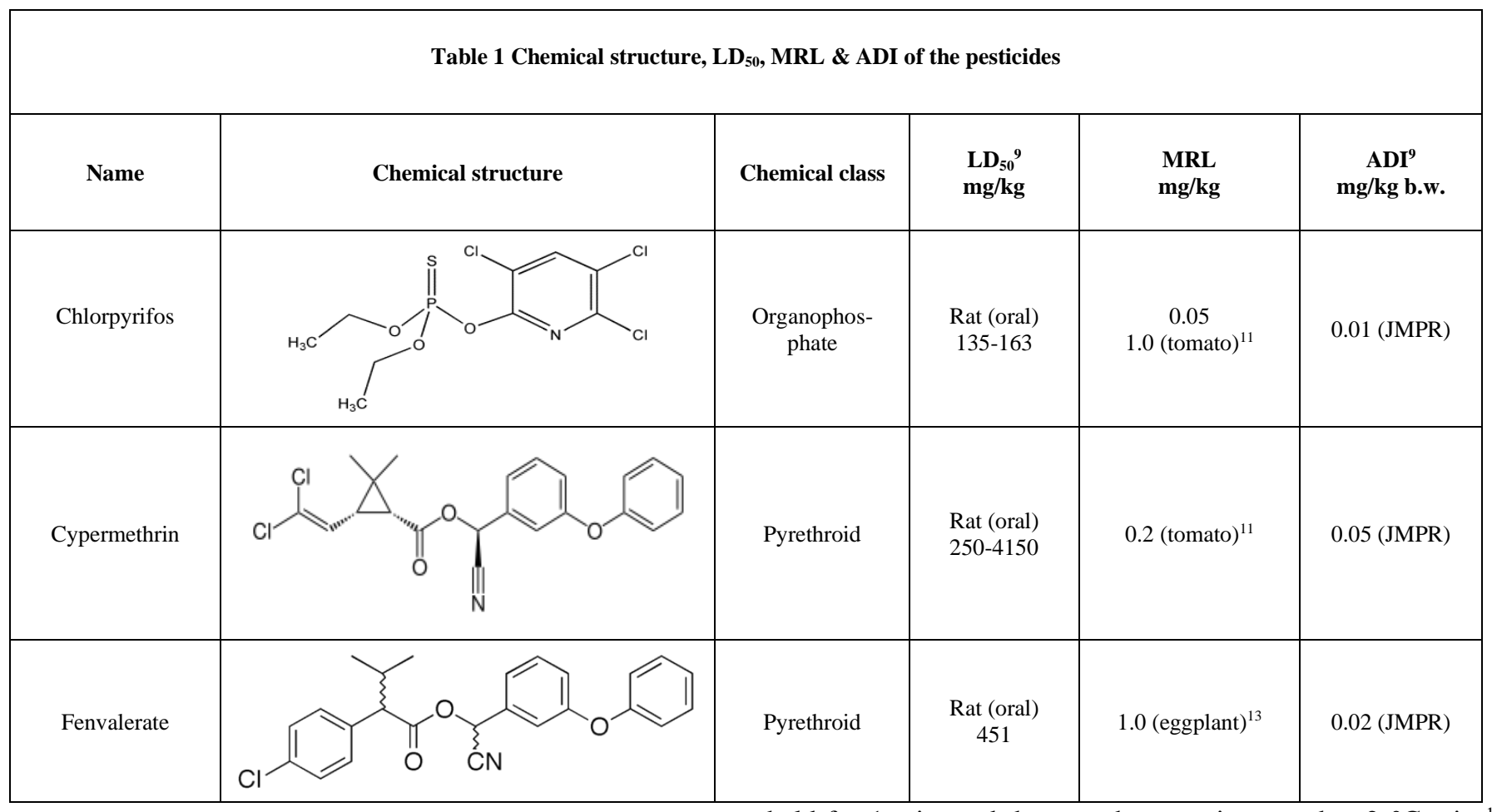

\section{Extraction Process:}

$20 \mathrm{~mL}$ ethyl acetate was added to $10 \mathrm{~g}$ homogenized sample in $50 \mathrm{~mL}$ teflon tube and shaken for 1 minute in hand \& vortex for 1 min. $6 \mathrm{~g}$ anhydrous $\mathrm{MgSO}_{4} \& 1.5 \mathrm{~g} \mathrm{NaCl}$ were added and vortexed for $1 \mathrm{~min}$ and then centrifuged for 5 minutes at $4000 \mathrm{rpm} .10 \mathrm{ml}$ supernatant solution was taken in $100 \mathrm{~mL}$ round bottomed flask, evaporated in rotary evaporator and then reconstituted in $\mathrm{n}$-hexane $(2 \mathrm{~mL})$.

\section{E. Purification:}

A glass column (40 cm long \& $12 \mathrm{~mm}$ internal diameter) was packed with a $10.5 \mathrm{~g}$ mixture of aluminum oxide, florisil held for $1 \mathrm{~min}$. and then another was increased at $2{ }^{\circ} \mathrm{C} \mathrm{min}-1$ to $290{ }^{\circ} \mathrm{C}$; held for $3 \mathrm{~min}$. The column flow was $1.0 \mathrm{~mL} \mathrm{~min}{ }^{-1}$. Total program time was 31.00 minutes.

\section{G. Quality Assurance:}

At first the control vegetables (samples collected before pesticide spraying) matrices were confirmed that there were no pesticides by doing blank experiments. The recovery experiments were done with these control matrices. The recovery experiments were performed in three replicates at 2-3 fortification levels. The fortified samples were left to stand for $2 \mathrm{~h}$ to allow for the adsorption of pesticides onto the samples. 
These samples were then extracted, purified and analyzed following the aforementioned procedures.

The pesticide residues in the fortified, field and market samples were quantitatively determined by external standard method using peak area. The linear matrix matched calibration curves for all pesticides over six calibration levels, from 0.025-2.0 $\mathrm{mg} / \mathrm{L}$ were constructed by the direct injection of calibration standards into the GC and all standard curves were within the acceptable limits of the linearity criterion which are shown in Table 2.

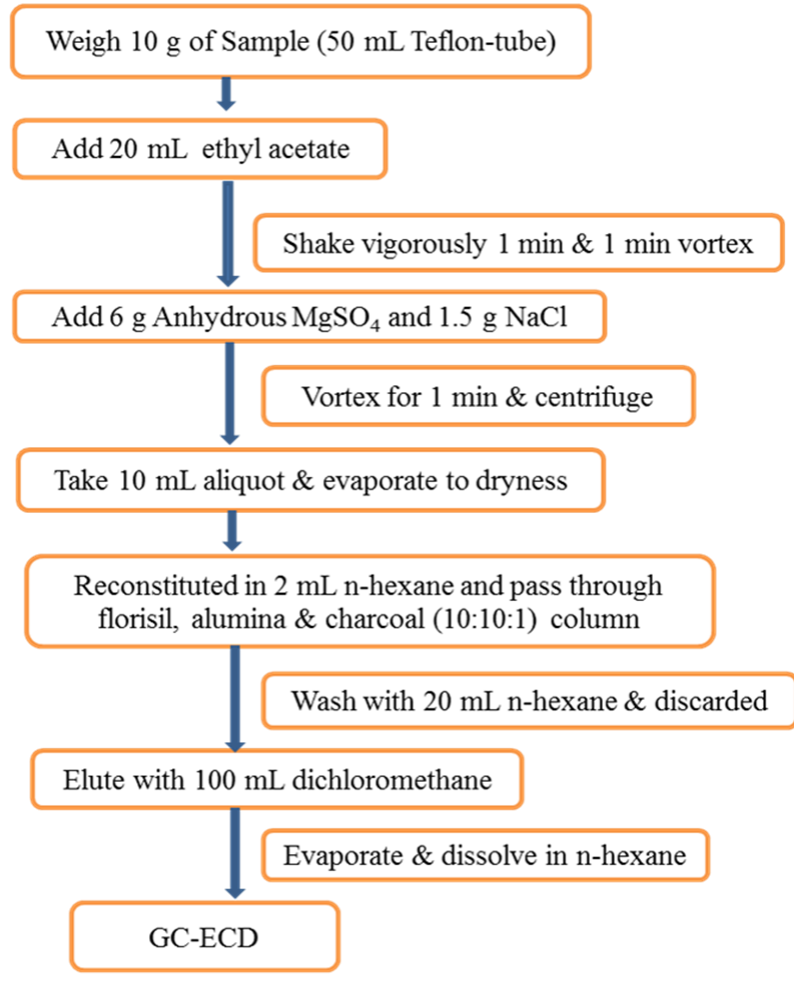

Fig. 2. Extraction and purification methods used in this experiment.

Before injecting the sample extracts triplicate solvent blank, reagent blank, vegetables blank (control samples) were injected to get smooth base line for assuring that there was not residual peaks of the targeted pesticides. The limit of detection (LOD) of the test compounds was determined using a signalto-noise ratio of 3 with reference to the background noise obtained for the blank sample, whereas the limits of quantification (LOQ) were determined with a signal-to-noise ratio of 10 . was calculated via the following equation [12].

$\mathrm{ME} \%=($ Peak area of matrix standard - Peak area of solvent standard) $\times 100 /$ Peak area of solvent standard.

\section{RESULTS AND DISCUSSION}

\section{A. Matrix Effect:}

In quantitative analysis by gas chromatography matrix effect is defined as a foremost setback. It is regarded as a signal suppression or enhancement of the analytes due to the co-elution of matrix components with the analytes, resulting in poor analytical accuracy, linearity, and reproducibility [1314]. The signal response of the analytes can vary considerably from matrix to matrix and differs significantly in pure solvent and in matrix. Therefore, it is needed to use the matrixmatched standards to make calibration curve in order to nullify quantitative errors in pesticide residues analysis. This effect was rather mild and not so much significant [15].

\section{B. Specificity:}

The unnecessary compounds interfering with the analytes were examined by comparing the chromatograms of the standard, blank sample and fortified sample. There were no interference peaks at the retention time of chlorpyrifos, cypermethrin, and fenvalerate observed.

\section{Linearity:}

In this study, calibration curves were prepared in matrices that extracted from control matrix (eggplant and tomato) and the linearities, limits of detection (LODs) and limits of quantification (LOQs) were calculated which are shown in Table 2. Matrix matches calibration curves (fenvalerate in eggplant, cypermethrin \& chlorpyrifos in both eggplant \& tomato) were constructed in the range of $0.025-2 \mathrm{mg} / \mathrm{L}$. The linearity with a correlation coefficient of $\mathrm{r}^{2} \geq 0.99$ was excellent. The residual concentrations of cypermethrin, fenvalerate and chlorpyrifos in both the treated and market samples were determined using the matrix matched calibration curves developed herein.

\section{Limits of Detection and Quantification:}

The limit of detection (LOD) defined as the minimum concentration of analyte in the test sample that can be measured with a stated probability that the analyte is present at a concentration above that in the blank sample. On the other hand the limit of quantification (LOQ) implies the minimum concentration of analyte in the test sample that can be

Table 2 Name, correlation coefficients $\left(r^{2}\right)$, LODs, LOQs and recoveries of the tested pesticides

\begin{tabular}{|c|c|c|c|c|c|}
\hline & \multirow{2}{*}{ Pesticides \& Vegetables } & \multirow{2}{*}{ Linearity $\left(\mathrm{r}^{2}\right)$} & \multirow{2}{*}{$\begin{array}{c}\text { LOD \& LOQ } \\
(\mathrm{mg} / \mathrm{kg})\end{array}$} & & \multicolumn{2}{|c|}{${ }^{\mathrm{a}}$ Accuracy (\% recovery), Precision (\% RSD) (Spiking level, mg/kg) } \\
\cline { 4 - 6 } & & & Spiking level I & Spiking level II & Spiking level III \\
\hline Cypermethrin in tomato & 0.997 & $0.01,0.033$ & $87,8.45(0.05)$ & $102,5.38(1.0)$ & $97,4.64(0.25)$ \\
\hline Fenvalerate in eggplant & 0.995 & $0.002,0.0066$ & $98,3.85(0.25)$ & $107,7.34(0.5)$ & $85,6.72(1.0)$ \\
\hline chlorpyrifos in tomato & 0.998 & $0.002,0.0066$ & $89,6.83(0.025)$ & $95,9.15(0.05)$ & $103,3.61(0.1)$ \\
\hline
\end{tabular}

${ }^{\mathrm{a}}$ Mean of three replicate

The matrix effect (ME) was determined by using a standard solution prepared in sample extract and pure solvent. ME \% determined with acceptable precision (repeatability) and accuracy under the stated conditions of the test [16]. The LOD and LOQ were found $0.01 \mathrm{mg} / \mathrm{kg}$ and $0.033 \mathrm{mg} / \mathrm{kg}$ for the cypermethrin in tomato, $0.002 \mathrm{mg} / \mathrm{kg}$ and $0.0066 \mathrm{mg} / \mathrm{kg}$ for 
fenvalerate in eggplant, $0.002 \mathrm{mg} / \mathrm{kg}$ and $0.0066 \mathrm{mg} / \mathrm{kg}$ for chlorpyrifos in eggplant \& tomato, respectively (See Table 2).

\begin{tabular}{|c|c|c|c|c|}
\hline \multicolumn{5}{|c|}{$\begin{array}{c}\text { Table } 3 \text { Pesticide residues (Av. } \pm \text { SD, mg/kg) in vegetables at } \\
\text { various days following its application }\end{array}$} \\
\hline$\frac{\tilde{o}}{\tilde{E}}$ & $\begin{array}{c}\text { Day } \\
\text { after } \\
\text { spraying }\end{array}$ & $\begin{array}{l}\text { Cypermethrin } \\
\text { in tomato }\end{array}$ & $\begin{array}{l}\text { Fenvalerate } \\
\text { in eggplant }\end{array}$ & $\begin{array}{l}\text { Chlorpyrifos } \\
\text { in tomato }\end{array}$ \\
\hline $\begin{array}{l}\overline{0} \\
\overline{0}\end{array}$ & - & BDL & BDL & BDL \\
\hline \multirow{6}{*}{ 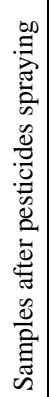 } & 0 & $0.39 \pm 0.04$ & $0.68 \pm 0.05$ & $1.73 \pm 0.07$ \\
\hline & 1 & $0.28 \pm 0.05$ & $0.45 \pm 0.03$ & $1.31 \pm 0.05$ \\
\hline & 3 & $0.15 \pm 0.017$ & $0.27 \pm 0.07$ & $0.95 \pm 0.13$ \\
\hline & 5 & $0.12 \pm 0.006$ & $0.16 \pm 0.02$ & $0.73 \pm 0.09$ \\
\hline & 7 & $0.07 \pm 0.002$ & $0.09 \pm 0.08$ & $0.54 \pm 0.04$ \\
\hline & 10 & $0.03 \pm 0.012$ & $0.05 \pm 0.01$ & $0.24 \pm 0.02$ \\
\hline
\end{tabular}

\section{E. Recovery:}

The extraction efficiency was assessed by doing recovery experiment. The recovery experiments were done with control samples collected from field before pesticide spraying which were initially confirmed that there were no pesticides. The recovery experiments were performed in three replicates at three fortified concentrations. The recoveries were $87-102 \%$ for cypermethrin in tomato, 92-107\% for fenvalerate in eggplant and $89-103 \%$ for chlorpyrifos in tomato with precision below than $10 \%$.

\section{F. Dissipation of Pesticides in Field Samples:}

Farmers in our country are applying pesticides in their field for crop productivity and selling the crops directly into the markets. Concerning in food safety \& security, the study was designed to reproduce the way of using pesticides in the real fields and the samples available in the market for the consumers. The amounts of Chlorpyrifos, cypermethrin and fenvalerate residues found in different vegetables after variable days of treatment with pesticides are reported in Table 3 .

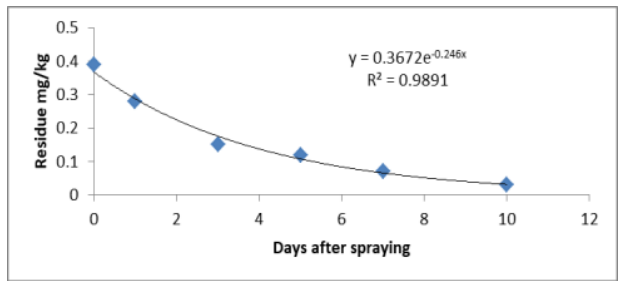

Fig. 3. Dissipation curve of cypermethrin in tomato

Discussing with farmers, it was selected the vegetables fields where pesticides were not applied within 10 days. No residues were detected on blank vegetables collected from the same fields before pesticides spraying. The sample collection was started after 2 hours of pesticides spraying. The pesticides were dissipated with time. The maximum residue levels were detected on 0 (zero) day. The residue concentrations of cypermethrin were found $0.39 \mathrm{mg} / \mathrm{kg}$ in tomato on 0 (zero) day and $0.03 \mathrm{mg} / \mathrm{kg}$ (87\% dissipation) in tomato after 10 day. The residue concentrations of fenvalerate were found 0.65 $\mathrm{mg} / \mathrm{kg}$ on 0 (zero) day and $0.05 \mathrm{mg} / \mathrm{kg}$ (86\% dissipation) in eggplant after 10 day. Similarly, the residue concentrations of chlorpyrifos were found $1.73 \mathrm{mg} / \mathrm{kg}$ in tomato on 0 (zero) day and $0.24 \mathrm{mg} / \mathrm{kg}$ (78\% dissipation) in tomato after 10 day. This result indicates that the percentage of dissipation of cypermethrin and fenvalerate on different vegetables are similar $(86-87 \%)$ but chlorpyrifos dissipates slowly $(78 \%)$ with time. The dissipation patterns with time have been shown in Figure 3 for cypermethrin in tomato, in Figure 4 for fenvalerate in eggplant and in Figure 5 for chlorpyrifos in tomato. The amount of residues gradually decreases with the increase of time elapsed for all the three pesticides. As the amount of chlorpyrifos residue is high on zero day and also the rate of dissipation is lower than other two pesticides studied so it will take longer time to be disappeared from the vegetable completely. These results suggest that chlorpyrifos stays on vegetables for longer time and hence farmers should allow considerable days after spraying to harvest vegetables.

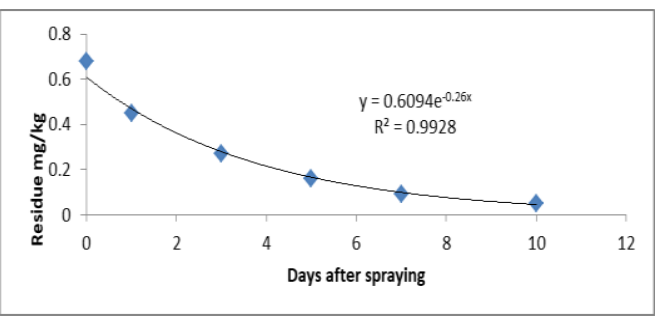

Fig. 4. Dissipation curve of fenvalerate in eggplant.

The above results can be explained well by calculating halflive of these three pesticides. The decreasing of concentration of the pesticides followed a first-order kinetics pattern. The half-life $\left(\mathrm{t}_{1 / 2}\right)$ was calculated by the formula $\mathrm{t}_{1 / 2}=\ln 2 / k$, in which the constant $k$ (Kappa) is the slope of the linear regression $\left(\mathrm{A}=\mathrm{A}_{0} \mathrm{e}^{-\mathrm{kt}}\right)$. The half-life of cypermethrin was calculated 3.3 days in tomato. Similarly for fenvalerate it was found 4.08 days in eggplant. Also half-life of chlorpyrifos was found 4.33 days in tomato. These results are well agreed with the above results.

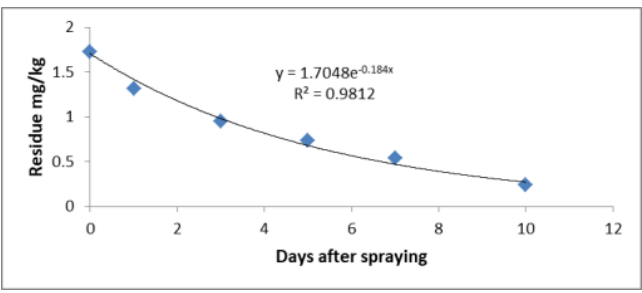

Fig. 5. Dissipation curve of chlorpyrifos in tomato.

On the context of maximum residue limits (MRL), it can be observed from Table 3 that Cypermethrin residues went below the MRL value at 3 days in tomato $(0.2 \mathrm{mg} / \mathrm{kg})$ and 
fenvalerate residues went below MRL value $(1.0 \mathrm{mg} / \mathrm{kg})$ at 0 day in eggplant. One the other hand Chlorpyrifos residues went below the MRL value $(1.0 \mathrm{mg} / \mathrm{kg})$ at 3 days after spraying in tomato. These results suggest that if Cypermethrin and Chlorpyrifos are sprayed on tomato the cultivators should allow minimum 3 days to harvest the vegetables but in case of fenvalerate spray it is safe anytime.

\section{G. Analysis of Market Samples:}

Eggplant and tomato samples of the same cultivar's variety were purchased from three local markets of Savar, Cumilla and Mymensingh two times. The amounts of pesticide residues found are listed in Table 4. It is noted that Cypermethrin was detected in tomato samples but no pesticides were found in eggplant samples. However, the amount of Cypermethrin was much lower than the MRL value. The vegetables might be picked up after reasonable interval between two consecutive insecticide sprays.

\begin{tabular}{|c|c|c|c|}
\hline \multicolumn{4}{|c|}{ Table 4 Pesticide residues (Av. \pm SD, mg/kg) in vegetables } \\
collected from three markets \\
\hline \multirow{2}{*}{ Market } & Sampling & Eggplant & Tomato \\
\hline \multirow{2}{*}{ Savar } & $1 \mathrm{st}$ & $\mathrm{BDL}$ & $\mathrm{BDL}$ \\
\cline { 2 - 4 } & $2 \mathrm{nd}$ & $\mathrm{BDL}$ & $\mathrm{Cp}=0.0065 \pm 0.0007$ \\
\hline \multirow{2}{*}{ Cumilla } & $1 \mathrm{st}$ & $\mathrm{BDL}$ & $\mathrm{Cp}=0.043 \pm 0.004$ \\
\cline { 2 - 4 } & $2 \mathrm{nd}$ & $\mathrm{BDL}$ & $\mathrm{Cp}=0.039 \pm 0.002$ \\
\hline \multirow{2}{*}{ Mymensingh } & $1 \mathrm{st}$ & $\mathrm{BDL}$ & $\mathrm{Cp}=0.056 \pm 0.004$ \\
\cline { 2 - 4 } & $2 \mathrm{nd}$ & $\mathrm{BDL}$ & $\mathrm{Cp}=0.025 \pm 0.001$ \\
\hline
\end{tabular}

\section{H. Health Risk Assessment:}

Estimated daily intake (EDI) of pesticide residues was calculated by multiplying the residual pesticide concentration $(\mathrm{mg} / \mathrm{kg})$ by the food consumption rate $(0.345 \mathrm{~kg} /$ person/day $)$ and dividing by a body weight of $60 \mathrm{~kg}$ for an adult people [17]. The Maximum Residue Limit (MRL) for cypermethrin in tomato is $0.2 \mathrm{mg} / \mathrm{kg}$, eggplant is $0.03 \mathrm{mg} / \mathrm{kg}$, according to Codex Alimentarius Commission [18-19] and the Acceptable Daily Intake (ADI) for human is $0.05 \mathrm{mg} / \mathrm{kg}$ body weight. The health risk index (HI) was also calculated. The HI showed that cypermethrin residues in all vegetables were found less than 1 $(\mathrm{HI}<1)$. From the concentrations of cypermethrin residues obtained, dietary exposure and health risks were calculated for adult. The statistic of daily food intake of an adult person of our country exposes that vegetables are in third position after rice, cereal and fish which give the daily food consumption in weight [20]. When $\mathrm{HI}$ is less than 1 , the food concerned is considered as acceptable. If the value is greater than 1 the food is considered a risk to the consumer [21-22]. Most of the vegetable samples were not harmful to health as all samples had cypermethrin lower than the MRL values [23]. World Health Organization has settled MRL for pesticide residues in different vegetables. In line with that very recently Bangladesh Food Safety Authority has enacted a regulation titled "Chemical Contaminants, Toxins and Harmful Residues" [24].

\section{CONCLUSION}

The method achieved good validation results (good repeatability/RSD and accuracy/recovery) within a short time. Results showed that all pesticides went below the MRL values very quickly. So the applied dose of pesticides by the farmer in the field to control pests in vegetables should be lower or pre-harvest interval should be longer. As a result, all samples were lower the MRL, so the vegetables samples might not competent to serious health hazard.

The most serious alarm about the pesticide use is its hazardous effects on different components of the environment. In Bangladesh context, the vegetables growers have been using the pesticides frequently to have advanced and pest free harvest. But the overdoses of pesticides make the residue problematic, which might contaminate our food and environment. Recently a multiplicity of Good Agricultural Practices (GAP) codes, standards and regulations has been developed by various food industry and producers organizations in first world countries. Bangladesh being a developing country, we need to develop a culture of Good Agricultural Practice to ensure safety and quality of product in the food chain, to capture new market advantages by modifying supply chain governance, to improve natural resources use, workers health and working conditions, and to create new market opportunities for farmers and exporters. We need to train our farmers, retail suppliers and consumers Good Agricultural Practices that address environmental, economic and social sustainability for on-farm processes, and result in safe and quality food.

There is always a time gap between the harvest and availability of vegetables in the local market. It is not enough to deliver manufacturers simply with a manual of food safety guidelines and skillful implementation and documentation. From these studies it is worthwhile for the consumers to keep vegetables at ambient temperature rather than store in a refrigerator for 2-3 days. Keeping the view in mind of the above reports, we want to suggest our Bangladeshi farmers to follow the Good Agriculture Practices of safe and quality food for healthy future generation.

\section{ABBREVIATIONS USED}

MRLs = Maximum Residue Limits; GC-ECD = gas chromatography with electron capture detector; i. d. = internal diameter; $\mathrm{ND}=$ not detected; $\mathrm{SD}=$ standard deviation; $\mathrm{RSD}=$ relative standard deviation; $\mathrm{RT}=$ retention time; $\mathrm{BDL}=$ Below Detection Limit, $\mathrm{Cp}=$ Cypermethrin.

\section{ACKNOWLEDGMENT}

This project was supported with a financial assistance from the Ministry of Science and Technology, Govt. Republic of Bangladesh and carried out with the experimental support of the Department of Chemistry, University of Dhaka, Bangladesh. 


\section{REFERENCES}

[1] G. H. Okhawa, H. Miyagawa and P. W. Lee, "Pesticide chemistry, crop protection, public health, environmental safety", Wiley, USA, 2007.

[2] C. M. Torres, Y. Pico and J. Manes, "Determination of pesticide residues in fruit and vegetables," J. Chromatogr. A., Vol. 754, No. 1-2, 1996, pp. 301-331.

[3] C. M. Torres, Y. Pico and J. Manes, "Comparison of octadecylsilica and graphitized carbon-black as materials for solid-phase extraction of fungicide and insecticide residues from fruit and vegetables," J. Chromatogr. A., Vol. 778, No. 1-2, 1997, pp. 127-137.

[4] G. M. J. Tyler, "Wodsworth/Thomson learning," Amazon Publishers, USA, 2002.

[5] G. S. Sodhi, "Fundamental concepts of environmental chemistry," Alpha Science International Ltd., Delhi, India, 2000.

[6] Z. M. Chen and Y. H. Wang, "Chromatographic methods for the determination of pyrethrin and pyrethroid pesticide residues in crops, foods and environmental samples," J. Chromatogr. A., Vol. 754 No. 1-2, 1996, pp. 367-395.

[7] A. Colume, S. Cardenas, M. Gallego and M. Valcarcel, "Semiautomatic multiresidue gas chromatographic method for the screening of vegetables for 25 organochlorine and pyrethroid pesticides," Anal. Chim. Acta, Vol. 436, No. 1, 2001, pp. 153-162.

[8] Chlorpyrifos Technical Fact Sheet, National Pesticide Information Center, Oregon State University Extension Services, USA, 2009. http://npic.orst.edu/factsheets/chlorptech.pdf.

[9] C. D. S. Tomlin, "The pesticide manual," 14th ed., Publisher: British Crop Production Council, UK, 2006.

[10] T. A. Miller and V. L. Salgado, "The mode of action of pyrethroids on insects, The Pyrethroid Insecticides," Leahey JP ed., Taylor \& Francis, London, 1985, pp. 43.

[11] M. Anastassiades, S. J. Lehotay, D. Stajnbaher and F. J. Schenck, "Fast and easy multiresidue method employing acetonitrile extraction/partitioning and "dispersive solidphase extraction" for the determination of pesticide residues in produce," J. AOAC Int., Vol. 86, 2003, pp. 412-431.

[12] B. Kanrar, S. Mandal and A. Bhattacharyya, "Validation and uncertainty analysis of a multiresidue method for 42 pesticides in made tea, tea infusion and spent leaves using ethyl acetate extraction and liquid chromatography-tandem mass spectrometry," J. Chromatogr. A., Vol. 1217, No. 12, 2010, pp. 1926-1933.

[13] C. Jansson, T. Pihlström, B. G. Osterdahl and K. E. Markides, "A new multi-residue method for analysis of pesticide residues in fruit and vegetables using liquid chromatography with tandem mass spectrometric detection," J. Chromatogr. A., Vol. 1023, No. 1, 2004, pp. 93-104.

[14] A. Kruve, A. Kunnapas, K. Herodes and I. Leito, "Matrix effects in pesticide multi-residue analysis by liquid chromatography-mass spectrometry," J. Chromatogr. A., Vol. 1187, No. 1-2, 2008, pp. 58-66.

[15] B. Kmellar, P. Fodor, L. Parefa, C. Ferrer, M. A. MartinezUroz, A. Valverde and A. R. Fernandez-Alba AR, "Validation and uncertainty study of a comprehensive list of 160 pesticide residues in multi-class vegetables by liquid chromatography-tandem mass spectrometry," J. Chromatogr. A., Vol. 1215, No. 1-2, 2008, pp. 37-50

[16] Codex Alimentarius, International food standards, CXG 40-1993, Guidelines on good laboratory practice in pesticide residue analysis, 2010. http://www.fao.org/faowho-codexalimentarius/codex-texts/guidelines/en/

[17] X. Wang, T. Sato, B. Xing and S. Tao, "Health risks of heavy metals to the general public in Tianjin, China via consumption of vegetables and fish," Sci. Total Environ., Vol. 350, 2005, pp. 28-37.
[18] Codex Alimentarius, Guidelines on good laboratory practice in pesticide residue analysis CAC/GL 40-1993 (Revision 2003, amendment 2010), 2013.

[19] Codex Alimentarius, International food standards, CXG 842012, Principles and Guidance on the Selection of Representative Commodities for the Extrapolation of Maximum Residue Limits for Pesticides to Commodity Groups; CXG 90-2017, Guidelines on Performance Criteria for Methods of Analysis for the Determination of Pesticide Residues in Food and Feed, 2017. http://www.fao.org/faowho-codexalimentarius/codex-texts/guidelines/it/

[20] Report of the household income and expenditure survey (HIES), Bangladesh Bureau of Statistics, Ministry of Planning, Govt. Republic of Bangladesh, 2011.

[21] G. Darko and S. O. Acquaah, "Levels of organochlorine pesticides in meat," Int. J. Environ. Sci. Tech., Vol. 4, No. 4, 2007, pp. 521-524.

[22] F. Opoku and O. Akoto, "Antimicrobial and phytochemical properties of Alstonia Boonei extracts," Organic Chem. Curr. Res., Vol. 1, 2015, pp.137.

[23] MRLs for Pesticides in Foods, Korea Food \& Drug Administration, 2009.

[24] Chemical Contaminants, Toxins and Harmful Residues, Bangladesh Food Safety Authority, Bangladesh Gazette No: SRO No 183-Law 2017.

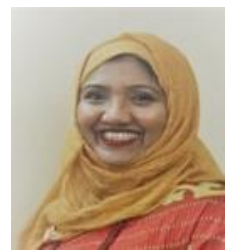

Farzana Khalil is an Assistant Professor in Chemistry of American International University-Bangladesh (AIUB). She received her $\mathrm{PhD}$ (Environmental Chemistry), MSc (Organic Chemistry) and Bachelor's degree in chemistry from University of Dhaka. She has more than fifteen years of professional experience \& holds several professional designations in research organizations, schools, colleges \& university. She was a guest researcher in Chonnam National University, South Korea. She received prestigious fellowships from ISP, NST \& HEQEP and government grant for research. Dr. Farzana has several national and international publications in highly recognized outlets. She has participated in seminars, conferences \& trainings in home and abroad. Her research interest includes areas of chemistry, food containments, natural products \& nano materials. She is a life member of Bangladesh Chemical Society and a research group member of BAN $01 \&$ BAN 04.

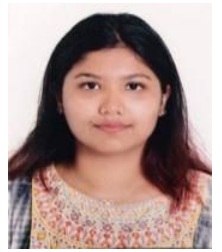

Maliyat Tarannum Maruf is a postgraduate student currently on her first year in Master of Environment and Sustainability in Monash University, Australia. She completed her bachelor's degree in Chemistry from Dhaka University. She has done internship from BCSIR and has worked as a research assistant in the atmospheric and environmental chemistry lab during her undergraduate.

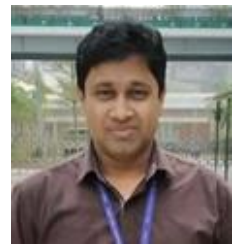

Mohammad Tariqul Islam is a Senior Assistant Professor of Chemistry at American International UniversityBangladesh (AIUB). Dr. Tariqul obtained $\mathrm{PhD}$ in Polymer and Nano-material science from Pukyong National University, South 
Korea. He received BSc and MSc in Applied Chemistry and Chemical Technology from University of Dhaka, Bangladesh. After $\mathrm{PhD}$ award he worked as a Lecturer at Dongseo University and completed his three years postdoctoral contract with two different laboratories in South Korea. Dr. Tariqul has 11 peer-reviewed research papers to his credit. He attended about twenty International conferences in South Korea, Spain and England. He awarded several times for his oral and poster presentation. His research interests lie in polymerization, supercritical carbon-dioxide $\left(\mathrm{scCO}_{2}\right)$ for synthesis of polymers, morphological studies and nano level structure analysis of block copolymers, nanocomposite of block copolymers and inorganic materials, sensors and hydrogels.

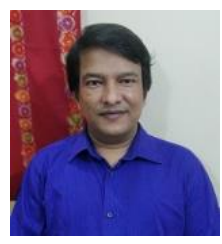

Mohammad Mahbub Rabbani is an Associate Professor of Chemistry at American International UniversityBangladesh (AIUB). He obtained his Bachelor and Master of Science degree in Chemistry from University of Chittagong, Bangladesh. Dr. Rabbani obtained his $\mathrm{PhD}$ degree in Informatics and Materials Engineering from Dong-Eui University, Busan, South Korea. Later, he earned postdoctoral research experience from Kyungpook National University, Deagu, and Inha University, Incheon, South Korea. His research area includes synthesis and characterization of metal nanoparticles, quantum dots, nanocomposites, multifunctional polymer nanocomposites, nanofibers, multi-layered thin films etc. Electrospinning technique to prepare composite nanofibers is one of his major research interests. He has published several research papers in various renowned peer-reviewed international journals and few book chapters from world renowned publishers. Dr. Rabbani is a reviewer of different international journals. Dr. Rabbani is a Life Member of Bangladesh Chemical Society (BCS).

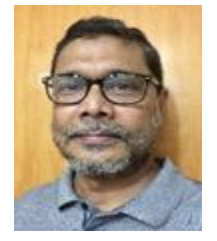

S. Mosaddeq Ahmed obtained B.Sc., and M.Sc. in Applied Chemistry \& Chemical Technology and $\mathrm{PhD}$ degree in Organic Chemistry from the University of Dhaka. Dr. Ahmed joined AIUB in 2003 and currently working as a Professor and Head of Chemistry under Faculty of Science and Technology. Dr. Ahmed is associated with an organic synthetic research group of the Department of Chemistry, University of Dhaka and some multidisciplinary projects involving environmental science, engineering, and nanotechnology at AIUB. As an outcome of his research association 21 papers already published in the local and international peer reviewed journals. His research interests are in the field of organic and nano material synthesis, natural products chemistry, environmental science \& analytical chemistry. Dr. Ahmed is a Life Member of Bangladesh Chemical Society (BCS). 